\title{
Can the Iberian Floristic Diversity Withstand Near-Future Climate Change?
}

\author{
Marshall J. Heap ${ }^{1}$, Alastair Culham ${ }^{1}$, Jonathan Lenoir ${ }^{2}$, Rosario G. Gavilán ${ }^{3}$ \\ ${ }^{1}$ Centre for Plant Diversity and Systematics, School of Biological Sciences, University of Reading, Berkshire, UK \\ 2Unité de Recherche "Ecologie et Dynamique des Systèmes Anthropisés" (EDYSAN, FRE3498 CNRS-UPJV), Jules \\ Verne University of Picardie, Amiens, France \\ ${ }^{3}$ Departamento de Biología Vegetal II, F. Farmacia, Universidad Complutense, Madrid, Spain \\ Email: ${ }^{\text {heapmj@gmail.com }}$
}

Received 12 October 2014; revised 13 November 2014; accepted 30 November 2014

Copyright (C) 2014 by authors and Scientific Research Publishing Inc.

This work is licensed under the Creative Commons Attribution International License (CC BY).

http://creativecommons.org/licenses/by/4.0/

(c) (i) Open Access

\begin{abstract}
We assess how effectively the current network of protected areas (PAs) across the Iberian Peninsula will conserve plant diversity under near-future (2020) climate change. We computed 3267 MAXENT environmental niche models (ENMs) at 1-km spatial resolution for known Iberian plant species under two climate scenarios $(1950-2000$ baseline $\& 2020)$. To predict near-future species distributions across the network of Iberian and Balearics PAs, we combined projections of species' ENMs with simulations of propagule dispersal by using six scenarios of annual dispersal rates (no dispersal, $0.1 \mathrm{~km}, 0.5 \mathrm{~km}, 1 \mathrm{~km}, 2 \mathrm{~km}$ and unlimited). Mined PA grid cell values for each species were then analyzed. We forecast $3 \%$ overall floristic diversity richness loss by 2020 . The habitat of regionally extant species will contract on average by $13.14 \%$. Niche movement exceeds $1 \mathrm{~km}$ per annum for $30 \%$ of extant species. While the southerly range margin of northern plant species retracts northward at $8.9 \mathrm{~km}$ per decade, overall niche movement is more easterly and westerly than northerly. There is little expansion of the northern range margin of southern plant species even under unlimited dispersal. Regardless of propagule dispersal rate, altitudinal niche movement of $+25 \mathrm{~m}$ per decade is strongest for northern species. Pyrenees flora is most vulnerable to near-future climate change with many northern plant species responding by shifting their range westerly and easterly rather than northerly. Northern humid habitats will be particularly vulnerable to near-future climate change. Andalusian National Parks will become important southern biodiversity refuges. With limited human intervention (particularly in the Pyrenees), we conclude that floristic diversity in Iberian PAs should withstand near-future climate change.
\end{abstract}

${ }^{*}$ Corresponding author. 
Keywords

Biodiversity, Climate Change, MAXENT, Plants, Portugal, Spain, Species Distribution Model

\section{Introduction}

The bulk of peer-reviewed literature on geographical patterns of species range shifts under contemporary and future climate change has focused on unidirectional (upward or poleward) and often unidimensional (latitudinal or elevational) range shifts. For instance, using a meta-analysis encompassing the animal and plant kingdoms, Chen and colleagues [1], observed a median rate of $11.0 \mathrm{~m}$ per decade upward and $16.9 \mathrm{~km}$ per decade poleward in species range shifts under contemporary climate change: two and three times faster than previously reported [2]. Still these are general tendencies and, as Chen and colleagues went on observing, there is a significant minority of species bucking these trends such as the downhill movement of $25 \%$ of the species they examined [1]. While the consensus among published research is poleward and upward movements of species in response to a warming climate, recent studies observe that this is not at all uniform [3]-[7]. Reliance on overall rates of poleward movement is an over simplification of what is a complex phenomenon that affects individual species differently [5]. Alternatively, by considering climate niche tracking of species individually, Groom has shown omnidirectional plant species distribution movement in all four British regions examined with few species distributions showing a clear northward azimuth of movement [8]. There were no distinct trends in climatic niche movement direction possibly also due to the numbers of plant species considered (238 to 423 depending on region).

The geographic isolation of the Iberian Peninsula renders external species immigration from more southern regions difficult without human intervention for most plant groups. Because of this and the fact that species extirpation through range shifts is very likely under future climate change, the Iberian Peninsula will likely suffer from biotic attrition, which is the loss of biodiversity that happens when the number of species emigrating exceeds the number of species immigrating within a given area [9] [10]. And yet, the Iberian Peninsula hosts a large proportion of Europe's plant diversity [11], including many endemics and northern species having their southern limits occurring there. Human land-use will further amplify the risks of extinction for those species across Iberia. A recent study [12] has demonstrated that protected areas (PAs) in Europe are expected to retain climatic suitability for species better than unprotected areas and attribute this to the generally mountainous terrain occupied by these PAs - particularly pertinent across the Iberian Peninsula. Therefore, the network of PAs in the Iberian Peninsula can be used to forecast the minimum biodiversity losses one can expect under future climate change.

Thuiller and colleagues conducted a European study evaluating the effects of projected climate change on the diversity of 1350 European plants at 50-km spatial resolution [13]. Under the most aggressive zero migration case (A1-HadCM3 climate scenario), Thuiller and colleagues concluded that species loss in north-central Spain could exceed $80 \%$ by 2080 [13]. However, at such coarse spatial resolutions ( $\gg 1 \mathrm{~km}^{2}$ ), species distribution models fail to capture spatial variability in temperature over tens or hundreds of meters [14]. Caution is therefore required in interpreting extinction predictions from such coarse-resolution models [15]. Though across a much smaller spatial extent covering the European Alps, Dullinger and colleagues have forecasted extinction risks for 150 high-mountain plant species under twenty-first-century climate change at 100-m spatial resolution [16]. Such very fine-resolution models are especially needed to study the fate of biodiversity within high mountain ecosystems, but the drawbacks are a limited spatial extent and a limited number of study species to avoid time-consuming computations. Indeed, major factors driving the choice of a coarse spatial resolution model are compute times and computer memory limitations though these obstacles can be overcome to perform large-scale geographic studies at fine spatial resolution with cluster computing facilities [17].

In accounting for species dispersal, Thuiller and colleagues discussed the need to identify suitable migration rates per species, and account for variation among populations, landscape fragmentation, human-mediated dispersal, etc. [18]. Yesson and Culham argued that man-mediated dispersal was the only option for Mediterranean Cyclamen migration because their natural dispersal rate was much slower than that would be needed to keep up with climate change driven migration [19]. For large-scale high-resolution studies, excessive compute times are 
again a major impediment. So, simpler and more pragmatic solutions are required to at least circumscribe the phenomenon. For instance, extreme scenarios involving either zero or unlimited propagule dispersal rates have been widely used [19]. Such scenarios assume a fixed $100 \%$ rate of establishment success at newly available sites and no potential persistence of declining remnant populations under deteriorating conditions. Unrealistic as they might seem, these two extreme scenarios are commonly used to delimit the possible changes in species distribution under climate change scenarios. Major climate studies have tended to use long-term forecasts of biodiversity change looking ahead to 2080 . However, long-term climate models are subject to greater data uncertainty than near-term models. Furthermore, near-term forecasts are much more important because politicians and landscape managers usually don't take long-term but rather short- or near-term decisions. Besides, near-future projections can identify immediate trends in the movement of species climate envelopes and enable human intervention to be focused in high biodiversity areas projected to resist climate change.

With this background, we designed this study to examine the potential effects of near-future (2020) climate change on 3267 plant species across the network of PAs in the Iberian Peninsula at 1-km spatial resolution considering various propagule dispersal rates. We aimed to forecast near-future changes in Iberian flora distribution across this network of PAs by using multifaceted (omnidirectional, multidimensional and multicriteria) analyses [7]. We also aimed to identify critically endangered flora species and vulnerable habitats where host flora will not withstand near-future climate change. By focusing only on PAs rather than the entire Iberian Peninsula, we have concentrated on areas with little or no human intervention where the computed floristic diversity is most likely to be found.

\section{Data \& Methods}

\subsection{Data and Modelling Methodology}

Heap, Culham and Osborne [17] used MAXENT [20] environmental niche models (ENMs) to predict species probability of occurrence for 4209 Euro/Mediterranean plant species at 1-km spatial resolution across the Mediterranean Basin defined by the geographical coordinates $50^{\circ} \mathrm{N}, 26^{\circ} \mathrm{S},-10^{\circ} \mathrm{W}, 40^{\circ} \mathrm{E}$ and under four climate scenarios (baseline 1950-2000, 2020, 2050 \& 2080). MAXENT models were computed using 22 environmental layers consisting of: 19 BIOCLIM layers [21]; one elevation layer; one soil layer [22]; and one land-use layer [23]. Each MAXENT species ENM weighted the environmental input layers according to their relevance to that specific species' distribution. Given that the Iberian Peninsula covers a wide range of habitats this methodology was considered more appropriate than the selection of a smaller range of environmental layers as used by Pliscoff and colleagues in their limited study of 13 flora species in the Atacama desert [24].

Baseline climate (1950-2000) BIOCLIM data was downloaded from WorldClim (http://www.worldclim.org). Data on near-future (2020) climatic conditions data was downloaded from Climate Change, Agriculture and Food Security (http://www.ccafsclimate.org) elaborated with methodology developed by Ramirez and Jarvis [25]. Most of the plant species occurrence data came from GBIF (http://www.data.gbif.org) with remaining data from the University of Reading Herbarium listed as RNG in Index Herbariorum [26]. These data were then cleaned removing various errors [27], for example; extraneous records, duplications, taxonomic disambiguation, spatial coordinate imprecision and points missing environmental data using the filtering methodology described in Heap and Culham [28]. It was not possible to temporally filter as, except for more recent data, most of the data was undated. However, it is probable that much of the older data was collected in the 1950:2000 timeframe corresponding to the baseline climate period. As noted in Heap, Culham and Osborne [17], the species occurrence data used included data from a low resolution UTM grid that skewed projected biodiversity losses for France [17]. Consequently, we removed these data and recomputed the ENMs to remove this error source (Figure 1(a)). From the resulting pool of 4150 species, we extracted probability grids covering just the Iberian Peninsula and Balearics for 3267 Iberian plant species (see Appendix S1 in Supporting Information for a detailed list) under the baseline (1950-2000) and 2020 climate scenarios (Figure 1(b)). The 3267 studied species represent about $40 \%$ of the 8500 Iberian \& Balearics flora estimated by Castroviejo [29] and each plant species has a known Iberian range principally established from the following sources: Castroviejo [29], Casas [30], Rivas-Martínez and colleagues [31], Euro + Med [32], The Plant List [33], Ros and colleagues [34], Roskov and colleagues [35] \& Encyclopedia of Life [36]. We included native, non-native and crop species as they all potentially contribute to overall biodiversity. Interactions between these categories were outside the scope of this study. 


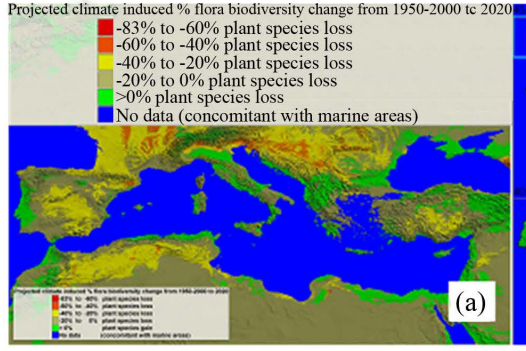

Mediterranean basin floristic diversity maps re-calculated to remove low resolution UTM grid species occurrence data.

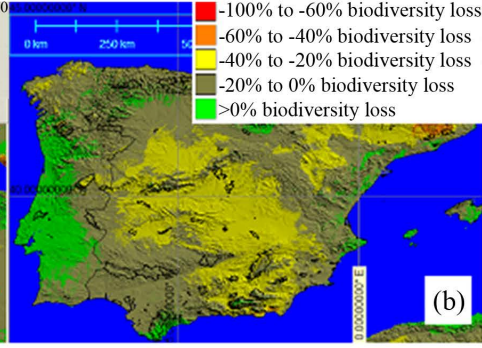

Iberian peninsula excised from previous map, PA boundaries superimposed and probability grids extracted for 3267 Iberian plant species.

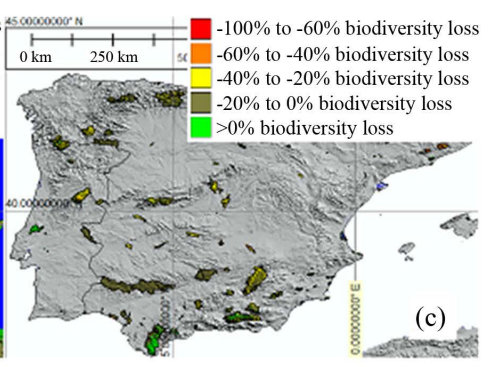

ENMs for Iberian plant species mined to obtain suitable habitat grid cells contained by the polygonal PA boundaries under baseline \& 2020 climate scenarios

Figure 1. Modelling methodology steps.

\subsection{Biodiversity Change Map for Iberian "Protected Areas"}

A mask representing the 294 Iberian PAs was then prepared using data from the World Database on Protected Areas (http://www.wdpa.org/) and ENMs for the previously defined Iberian plant species were mined to obtain suitable habitat grid cells contained by the polygonal park borders under the baseline climate and near-future climate scenarios (Figure 1(c)). Suitable habitat was defined by grid cells with values greater or equal to 0.1 similar to the approach used by Pittman and Brown [37]. This threshold was consistently applied to all species under both climate scenarios. Morin and Thuiller [38] have observed that "at the continental scale, niche-based models have been widely used in the last 10 years to predict the potential impacts of climate change on species distributions all over the world". The rough approximation to the fundamental niche described by these ENMs is based mainly on bioclimatic data. However, Araújo and colleagues [12] expressed their reservation that "using the full bioclimatic envelopes to assess the impacts of climate change on protected areas would amount to estimating species losses from areas where they might not occur, thus undermining the usefulness of the assessment". The solution to this problem offered by Araújo and colleagues [12] was to only consider species presence predicted by ENMs where it was confirmed by atlas records. The leading resource for European flora is the Atlas Florae Europaeae (AFE). As of December 2013, this atlas covers just over 20\% of European taxa-currently a significant limit on the number of taxa that could be considered in a biodiversity richness change study using the cross-validation approach proposed by Araújo and colleagues [12]. Consequently, our species presence cross-validation procedure was limited to plants belonging to the species pool of the Iberian Peninsula.

Accounting for species dispersal is a daunting challenge. Ideally we would handle this by grid cell but since there are hundreds of species per grid cell and several hundred thousand grid cells to consider, this becomes a monumental computing task. Consequently, we took a less intensive approach assuming unlimited dispersion within a focal PA and migration from other PAs at various distance intervals. Regarding external species immigration, there was only one species in our data north of the border between Spain and France that was sufficiently close to potentially migrate into our study region. The nearest Iberian PA to the southern Spanish border is $40 \mathrm{~km}$ away and we had only 21 non Iberian plant species in northern Africa within $30 \mathrm{~km}$ of the southern border. Consequently, we did not calculate potential species immigration to Iberia from neighbouring countries due to the paucity of proximate different species and insufficient number of proximate PAs. In determining unlimited species dispersal within a PA, where a species' environmental niche was present under the 2020 climate scenario then this was allowed where the species' environmental niche was also present under the baseline climate scenario in the same PA. For migration from other PAs, we considered six scenarios of annual dispersal rates; namely, zero, $0.1 \mathrm{~km}, 0.5 \mathrm{~km}, 1 \mathrm{~km}, 2 \mathrm{~km}$ and unlimited.

Aggregate species probability values were summed by PA grid cell for the two climate scenarios and the percentage change of biodiversity richness derived applying the formula described in Heap, Culham and Osborne [17].

\subsection{Species Environmental Niche Movement}

Species environmental niche directional movement represents the bearing in degrees derived from the azimuth 
drawn between the centre of mass of the species' distributions under the baseline and 2020 climate scenarios. The resulting species directional data vectors were then converted to a random VonMises distribution to which a Kuiper test was applied. A VonMises distribution of circular data is the equivalent of the normal distribution for linear data and the Kuiper test determined the extent to which the distribution differed from random. The distance moved by the centre of mass between the two climate scenarios was calculated using Euclidean geometry. This methodology is similar to that described in Groom [8].

\subsection{Horizontal/Vertical Niche Movements for "Northern" and "Southern" Species}

Horizontal range limit changes for "northern" and "southern" species were computed based on the methodology described by Brommer [39] where the change in range margin was plotted against change in distribution on a $\log 10$ scale. The range margin was defined as the median latitude of the 10 most marginal grid cells. Positive values for range margin change indicated northward movement and negative values southward movement. Distribution changes were calculated as the $\log 10$ proportion of baseline climate occupied grid cells over 2020 climate occupied grid cells. "Northern" species were defined as those plant species occupying at least 10 grid cells under each climate scenario with a southern range margin within the Iberian Peninsula. "Southern" species were similarly defined though this time with a northern range margin within the Iberian Peninsula. Vertical niche movement compared mean altitude changes of occupied PA grid cells with change in distribution. In each case, the " $y$ " intercept was then subject to a " $t$-test" to determine the probability $P$ of range movement.

\section{Results}

\subsection{Biodiversity Changes}

Figure 2(a) used zero species dispersal (from other PAs) but there were no observable changes at this scale regardless of the species dispersal scenario used.

For most Iberian PAs, the effects of species dispersal rate on mapped biodiversity richness change for the map legend ranges used is invisible. Picos de Europa National Park located near the northern Spanish coastline was a notable exception. As expected, biodiversity richness changes between the baseline and 2020 climate scenarios are positively correlated with increasing dispersal rates. There are no observable differences in biodiversity change between zero and $0.1 \mathrm{~km}$ per annum dispersal from other PAs (Figure 2(b)). Biodiversity change is similar for $0.5 \mathrm{~km}, 1 \mathrm{~km}$ and $2 \mathrm{~km}$ annual dispersal rates (Figure 2(c)). Figure 2(d) is included to circumscribe the maximum possible effect of species dispersal on biodiversity change but it is clearly an unrealistic scenario as it potentially would permit dispersal from a southern coastal PA to a northern coastal PA between the two climate scenarios. Figure 2(c) (at $1 \mathrm{~km}$ per annum) is the most realistic representation of biodiversity change for this national park where species dispersal results in slightly smaller diversity losses and slightly higher diversity gains than zero dispersal (Figure 2(b)).

The 3267 modelled species consisted of 3206 "persistent" species (i.e., computed to be present under both climate scenarios) and 61 "extirpated" species (computed to become locally extinct under the 2020 climate scenario). Persistent species were further classified in Table 1.

The 61 plant species computed to become locally extinct under the 2020 climate scenario represent a 1.87\% loss in overall biodiversity. However, there are a further 38 critically endangered plant species that will see a habitat contraction of $\geq 99 \%$ (regardless of dispersal scenario) so by 2020 , overall biodiversity loss may easily affect approx. 100 species or $3 \%$ of the 3267 plant species modelled.

Appendix S2 in Supporting Information provides a detailed list of extirpated and critically endangered species. Local extinctions (Table 2) are generally distributed in the north of the Iberian Peninsula with a mean latitude ranging from 42.0565 to 43.357 and mean longitude ranging from -6.7945 to +2.5206 . We defined critically endangered species (Table 2) as those whose distribution under the baseline climate will contract by $\geq 99 \%$. The general distribution pattern of this group is again the northern Iberian Peninsula with a range similar to that for local extinctions.

\subsection{Distribution Changes}

The 3206 persistent species will see an average contraction in their habitat of 13.14\% with 683 (21\%) of these species seeing a contraction of more than $50 \%$. Centre of mass movement will exceed $1 \mathrm{~km}$ per year for 963 or 


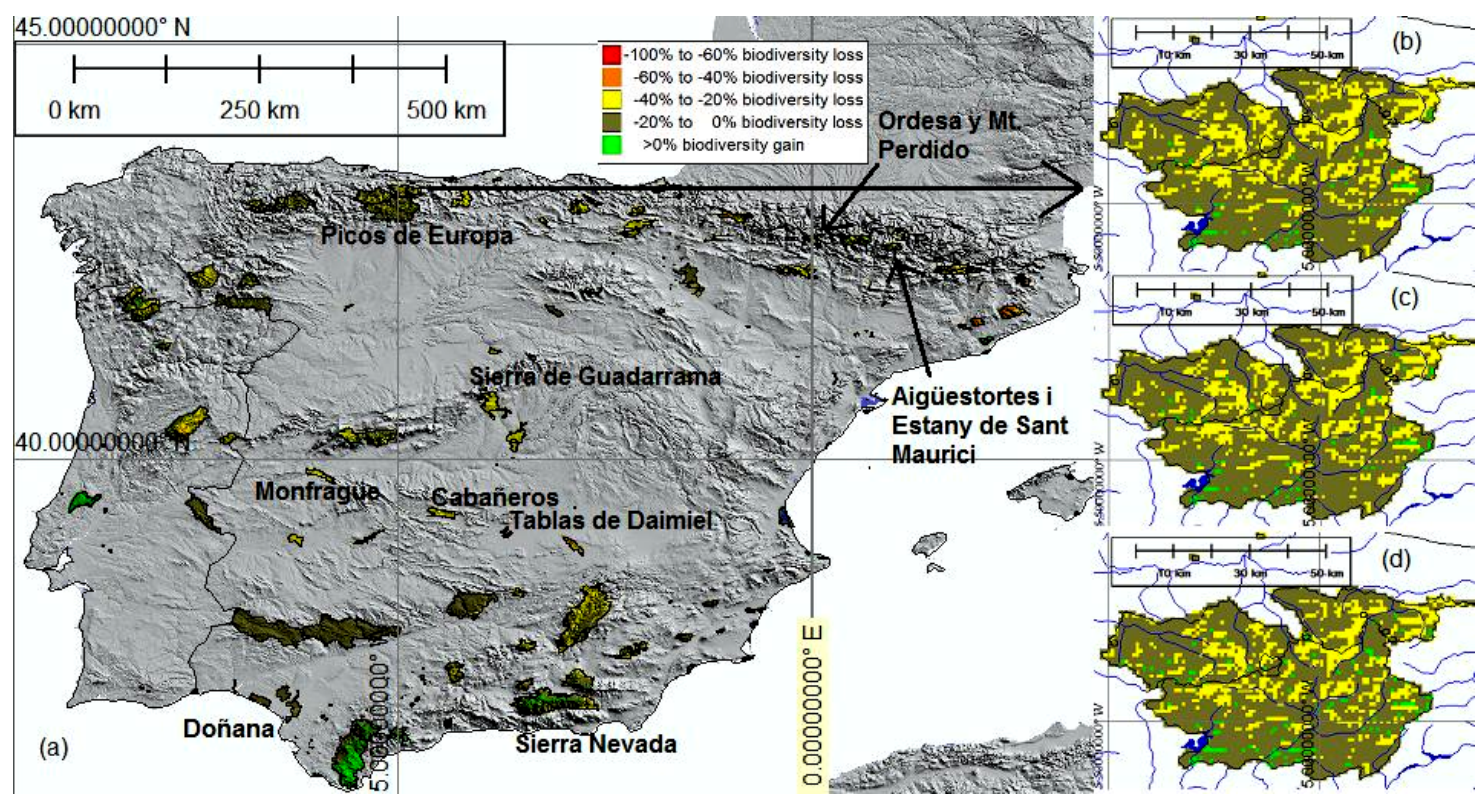

Figure 2. Percentage climate-induced biodiversity change in Iberian PAs (a) between 1950:2000 and 2020-zero species dispersal from other PAs. Zoom-in panel-Picos de Europa National Park. Yearly species dispersal rates from other PAs; zero (b), 1 km (c) \& unlimited (d).

Table 1. Approx. geographic ranges of "persistent” plant species in Iberia.

\begin{tabular}{ccc}
\hline Geographic class & Range & Number of species \\
\hline Northern species & Southern range margin in Iberia & 1390 \\
Southern species & Northern range margin in Iberia & 514 \\
Endemic species & Iberia & 464 \\
Ubiquitous species & Within, north and south of Iberia & 790 \\
Rare species $^{\mathrm{b}}$ & Iberia \& possibly elsewhere & 48 \\
Total persistent species $^{\mathrm{a}}$ & & $\mathbf{3 2 0 6}$ \\
\hline
\end{tabular}

${ }^{\mathrm{a}} 335$ species present in the southern half of Iberia \& 129 species in the northern half; ${ }^{\mathrm{b}}$ Present in less than ten $1 \mathrm{~km}^{2}$ grid cells.

roughly $30 \%$ of persistent species. Both these statistics were determined under the $1 \mathrm{~km}$ per year dispersal scenario.

For all persistent species, although the overall azimuth of niche movement is northerly, there are significant numbers of species showing westerly and easterly niche movement, especially for scenarios of low annual dispersal rates (Figure 3). The main contributors to this phenomenon are northern species (Figures 4(a)-(c)). Increasing northerly niche movement is positively correlated with faster species dispersal rates for persistent species where southern species are chiefly responsible for this movement (Figure $3 \&$ Figures 4(d)-(f)). The effect of species dispersal rates is minor on overall movement of northern species niches (Figures 4(a)-(c)) but for southern species, there is a radical change in direction/magnitude from somewhat westerly to strong northerly (Figures 4(d)-(f)). Kuiper test scores were highly significant $(P<0.01)$ for all species categories at all species dispersal rates.

Under the $1 \mathrm{~km}$ per annum species dispersal scenario, the southerly range margin of northern species will retreat northward at a rate of $8.9 \mathrm{~km}$ per decade $\left(P<2 \mathrm{e}^{-16}\right)$ (Figure 5(a)) between the two climate scenarios. Scenarios of higher dispersal rates from other PAs will reduce this trend to a small degree (Appendix S3: Table $1)$. 
Table 2. Computed local extinctions and critically endangered "persistent” plant species in Iberia.

\begin{tabular}{|c|c|c|c|}
\hline \multirow{2}{*}{$\begin{array}{l}\text { Mean altitudinal } \\
\text { distribution }\end{array}$} & \multirow{2}{*}{ Habitat } & \multicolumn{2}{|c|}{ Number of species } \\
\hline & & Local extinctions & Critically endangered \\
\hline$>2300$ masl & Alpine grasslands & 4 & 2 \\
\hline \multirow[t]{2}{*}{1700 to 2300 masl } & Mesic grasslands and meadows & 9 & 4 \\
\hline & Saxicolous & 1 & 1 \\
\hline \multirow[t]{4}{*}{650 to 1700 masl } & Freshwater & 5 & 4 \\
\hline & Mesic grasslands & 23 & 15 \\
\hline & Saxicolous & 1 & 3 \\
\hline & Other (weeds, local extinctions; forest, critically endangered) & 3 & 5 \\
\hline \multirow[t]{4}{*}{$<650$ masl } & Freshwater & 4 & 0 \\
\hline & Mesic grasslands & 9 & 0 \\
\hline & Saxicolous & 2 & 0 \\
\hline & Other (weeds) & 0 & 4 \\
\hline Totals & & 61 & 38 \\
\hline
\end{tabular}
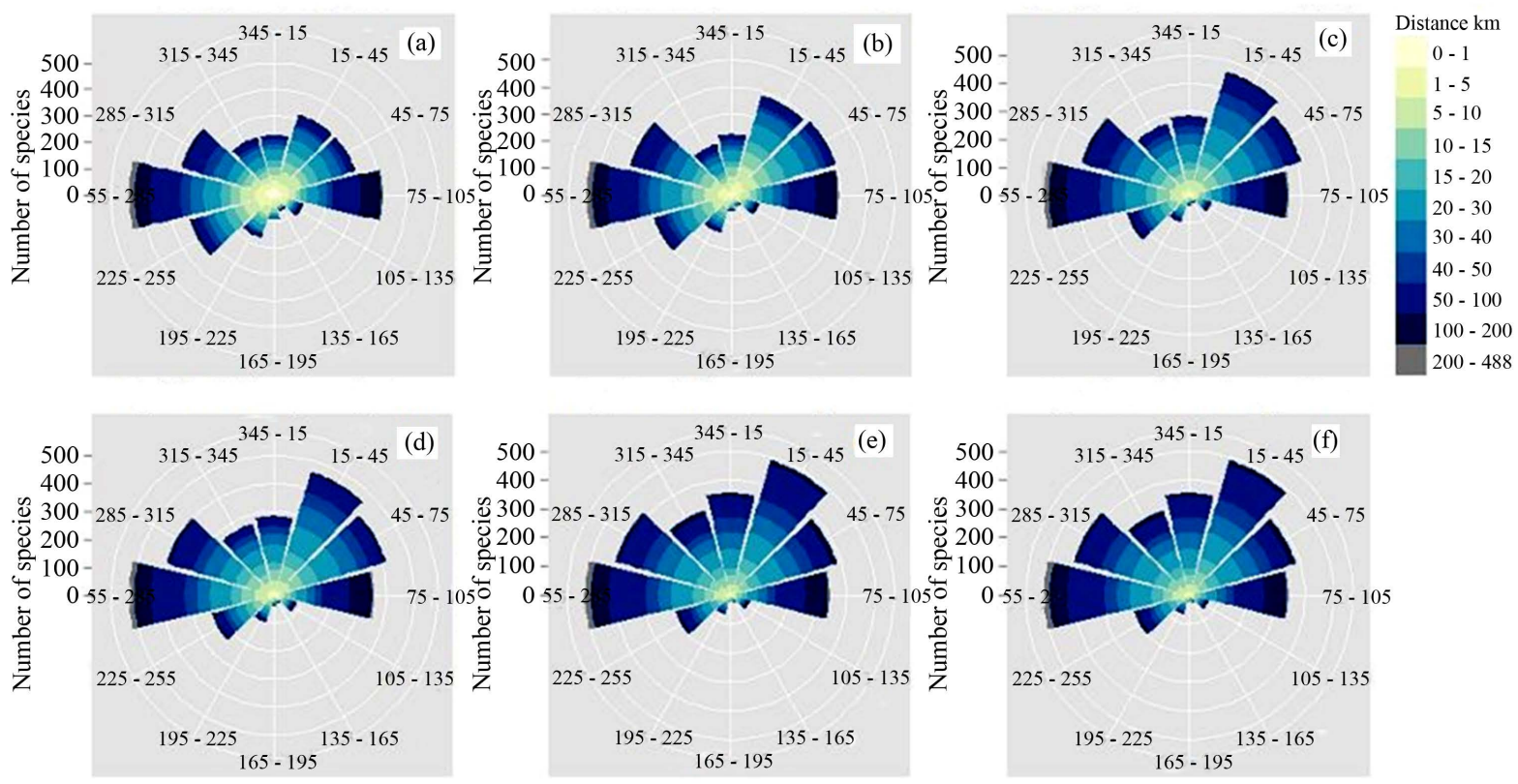

Figure 3. Directions and distance of movement of "persistent" species centre of mass. Migration rates represent yearly species dispersal rates from other PAs ((a)=0 km pa; (b) =0.1 km pa; (c) =0.5 km pa; (d)=1 km pa; (e) =2 km pa; (f) =unlimited).

We did not find any statistically significant changes in the northern range margin of southern species until the dispersal rate reached at least $0.5 \mathrm{~km}$ per year (Appendix S3: Table 2). Assuming an average $1 \mathrm{~km}$ per year dispersal rate, the habitat of southern species will expand northwards at a statistically significant $(P<0.02)$ rate of $1.3 \mathrm{~km}$ per decade. Overall distribution change is balanced between southern species with some species expanding and others contracting their ranges (Figure 5(a)).

Vertical niche movement is strongest for northern species (Figure 5(b)) whose overall decadal shift of $+25 \mathrm{~m}$ is highly significant $(P<2 \mathrm{e}-16)$ - see Table 3 . For southern species there is a highly significant $\left(P<2 \mathrm{e}^{-16}\right)$ overall vertical niche movement of $+5.5 \mathrm{~m}$ per decade which by contrast with northern species is more influ- 

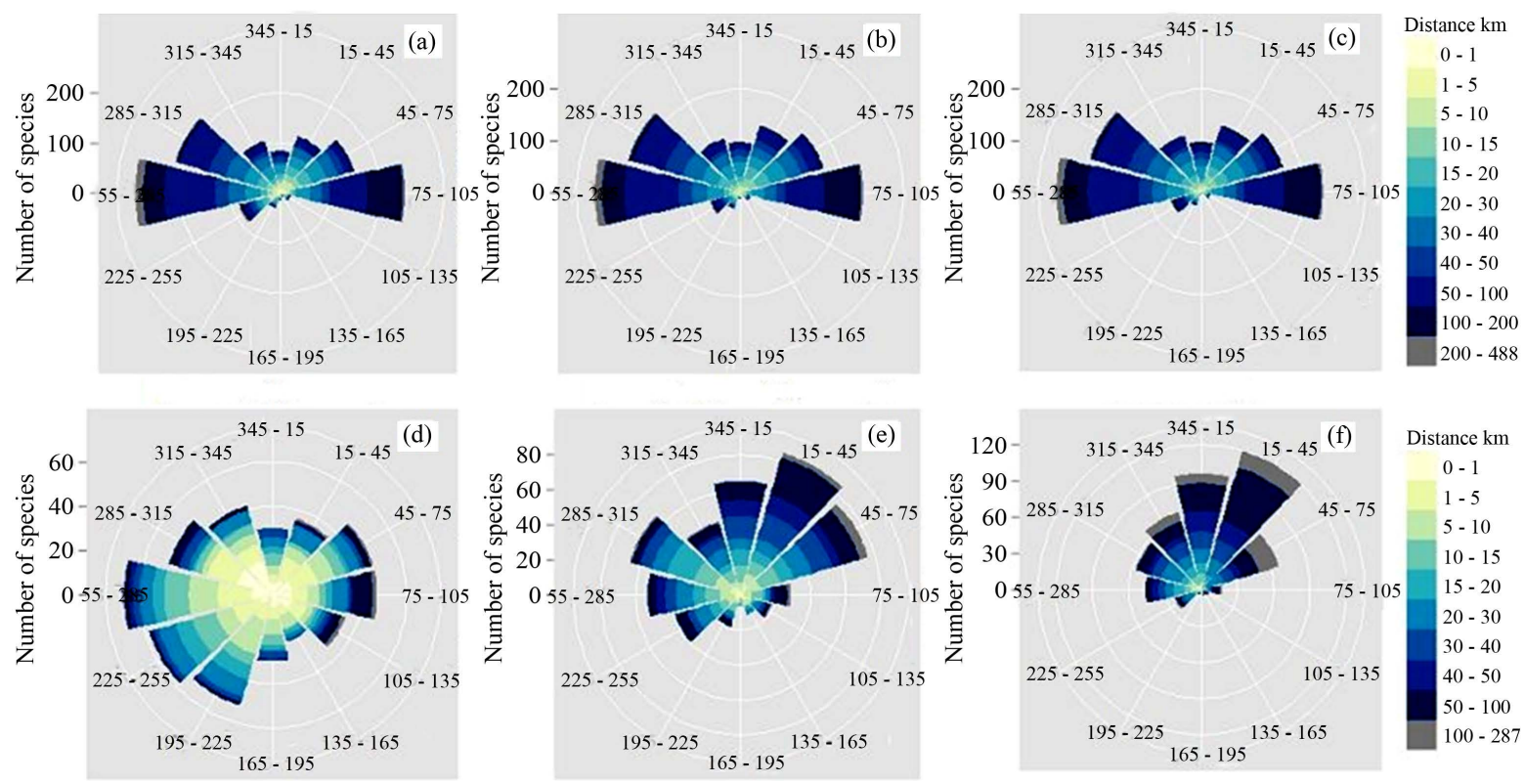

Figure 4. Directions and distance of movement at the centre of mass for both "Northern" (a, b, c) and "Southern" (d, e, f) species. Migration rates represent yearly species dispersal rates from other PAs ((a) =0 km pa; (b) =1 km pa; (c) =unlimited; (d) =0 km pa; (e)=1 km pa; (f) =unlimited).
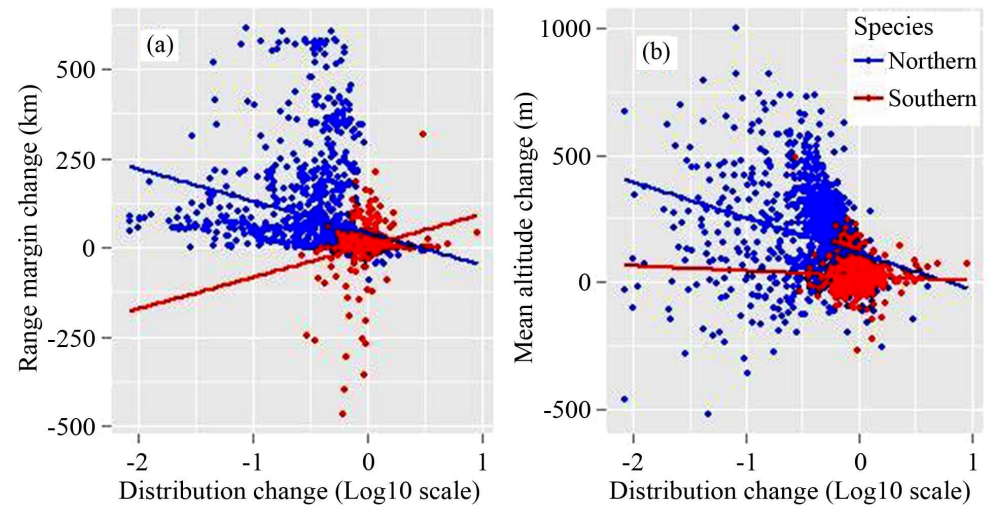

Figure 5. Northern/Southern species range margin changes (a) and Northern/Southern mean altitude change (b) respectively plotted against distribution change on a log10 scale. $1 \mathrm{~km}$ yearly species dispersal rates from other PAs.

enced by the migration rate (Table 4). There are more southern species than northern species exhibiting downward vertical niche movement (Figure 5(b)).

\section{Discussion}

Each ENM describes a plant species' range based on a computed range of associated environmental factors (as described in Data \& Methods). This methodology enabled us to conduct a macro level biodiversity study considering thousands of plant species and by adopting a relatively high level of spatial resolution $(1 \mathrm{~km})$, we were able to gain a detailed picture of regional variations in climate change as it affects plant biodiversity.

By circumscribing the dispersal phenomenon of species (zero vs unlimited dispersal), we have shown the maximum possible effect that an unlimited dispersal rate can have (Figure 2(b) and Figure 2(d)). The effects of species dispersal on our maps are generally imperceptible for most Iberian PAs and even where these effects were visible like Picos de Europa, they were small. An average dispersal rate for the 3206 persistent species modelled is likely to be less than $1 \mathrm{~km}$ p.a. In this context, Heubes and colleagues [40] capped dispersal rates at 
Table 3. Northern species vertical niche movement "t" test values for varying migration rates.

\begin{tabular}{cc}
\hline Migration rate & "Y" axis intercept $(\mathrm{m})^{\mathrm{a}}$ \\
\hline Zero & 113.29 \\
0.1 km per year & 113 \\
0.5 km per year & 112.38 \\
1 km per year & 113.33 \\
2 km per year & 113.73 \\
Unlimited & 113.88 \\
\hline
\end{tabular}

antercept " $P$ ” value \& Slope “ $P$ ” value $\leq 2 \mathrm{e}-16$ for all migration rates.

Table 4. Southern species vertical niche movement " $\mathrm{t}$ " test values for varying migration rates.

\begin{tabular}{cccc}
\hline Migration rate & "Y" axis intercept $(\mathrm{m})^{\mathrm{a}}$ & Intercept " $P$ ” value & Slope " $P$ " value \\
\hline Zero & 24.69 & $<2 \mathrm{e}-16$ & 0.0448 \\
0.1 km per year & 22.88 & $<2 \mathrm{e}-16$ & 0.0987 \\
0.5 km per year & 22.8 & $<2 \mathrm{e}-16$ & 0.112 \\
1 km per year & 24.56 & $<2 \mathrm{e}-16$ & 0.25 \\
2 km per year & 26.09 & $<2 \mathrm{e}-16$ & 0.384 \\
Unlimited & 28.93 & $<2 \mathrm{e}-16$ & 0 \\
\hline
\end{tabular}

$1 \mathrm{~km}$ p.a. to avoid unreliable future potential distributions for a biodiversity study involving 1390 plant species in Burkina Faso.

Where we indicate biodiversity loss, this refers to the absence of a viable environmental niche by 2020. Indeed, we assumed no potential persistence of declining remnant populations under deteriorating conditions. However, this does not necessarily mean that affected plant species will no longer be found in those areas, rather that it will become increasingly difficult for these species to reproduce and survive there. Similarly, our results need to be interpreted with caution since we assumed a fixed $100 \%$ rate of establishment success at newly available sites. This means that forecasted expansion trends in species range and biodiversity enrichment in some areas are unlikely to happen by 2020 due to a lower rate of establishment success at newly available sites.

\subsection{Biodiversity Losses Will Mostly Affect the Northern Flora}

Of the 61 species calculated to become locally extinct, several have large environmental niches within Iberian PAs under the 1950:2000 climate scenario (Appendix S2). Strikingly, all 61 of these species as well as all 38 critically endangered species have a distinctly northern current range. While the azimuth of overall niche movement is northward, there are distinct trends within Iberia that we will discuss next.

\subsection{Species Movements within Iberia Will Be Omnidirectional}

The azimuth of movement of persistent species niches is northerly where species migration from other PAs is unlimited and north-westerly where species migration from other PAs is zero (Figure 3). However, this overall movement belies two distinct westerly and easterly trends driven by northern species (Figures 4(a)-(c)). Extreme predicted shifts of the centre of mass for northern species are likely due to massive population extirpation in remotely located parks and the west/east layout of northern Iberian PAs is driving this. However, at smaller rates of niche movement (between 0 and $10 \mathrm{~km}$ ) Figures 4(a)-(c) reveal a similarly strong westerly/easterly trend so other factors must be at work. Two important factors will be local climate and topography. In the Iberian Peninsula winter rain is brought by north-west and westerly winds producing a strong precipitation gradient [41] 
as reflected by our analysis. Much of this terrain is mountainous (Figure 2(a)) and there are prominent north/ south oriented valleys particularly in the high Pyrenees. Thus, climatic niche movement is predominantly eastward or westward in search of cooler temperatures and wetter conditions, particularly so in northern Spain. Working at $1 \mathrm{~km}$ resolution rather than a coarser resolution enabled us to observe in detail this phenomenon.

\subsection{Can the Iberian Floristic Diversity Withstand Near-Future Climate Change?}

Our map of relative Iberian floristic diversity (Figure 6) shows many similarities with that of FernándezGonzález and colleagues: Figure 5.2 [11]. Apart from the north Atlantic Portugal/Spain coastline, there are strong correlations both for high and low biodiversity areas. We also agree with their observation that climatic displacement will exceed dispersal rates for many species.

As noted in the introduction, most Iberian PAs are in mountainous areas containing higher than average plant diversity (Figure 6). Except for the Pyrenees and central Spain, major Iberian PAs are generally in areas of biodiversity gain or low projected biodiversity loss (Figure 2(a)).

Many of the species predicted to be locally extinct or critically endangered under the near-future climate scenario are currently widely distributed in Europe and Asia. These species generally find, in the northern part of the Iberian Peninsula, their southern range limits so we are detecting contractions of their distribution range. In contrast with Fernández-González and colleagues [11], who predicted a higher influence of warming in northern Spain and lower water availability in the south, our results suggest that most of the taxa close to extinction or critically endangered are from northern areas such as the Pyrenees or Cantabrian range where they are linked to humid habitats. Hence, we expect not only warming but also lower rainfall to cause near-future biodiversity loss in northern Spain due to consequent increased soil moisture deficit, albeit remnant populations of plant species may still persist locally in enclaves of benign environmental conditions created by rough terrains [42]. The most vulnerable habitats to immediate species loss are those related to the presence of water and at altitudes between $650 \mathrm{~m}$ and $1700 \mathrm{~m}$ (Table 2).

The Pyrenees is the main area of high biodiversity facing the greatest threat from near-term climate warming. Centrally located protected areas like Ordesa y Monte Perdido National Park, Posests-Maladeta Park \& Aigüestortes i Estany de Sant Maurici National Park will generally fair better than elsewhere. Relocating species at higher altitudes within these PAs should allow for their survival in the wild given the pronounced westerly and easterly movement of climatic envelopes for many northern species (Figures 4(a)-(c)). However, this does assume that steps are taken to mitigate the impact that translocated species could have on the locally native flora [43].

Projected biodiversity loss for central Catalonia exceeds 40\% (Figure 2(a)). The Catalonian protected areas of Can Simo, Massís del Montseny \& Sant Llorenç del Munt i l’Obac will be particularly hard hit but Font Gro-

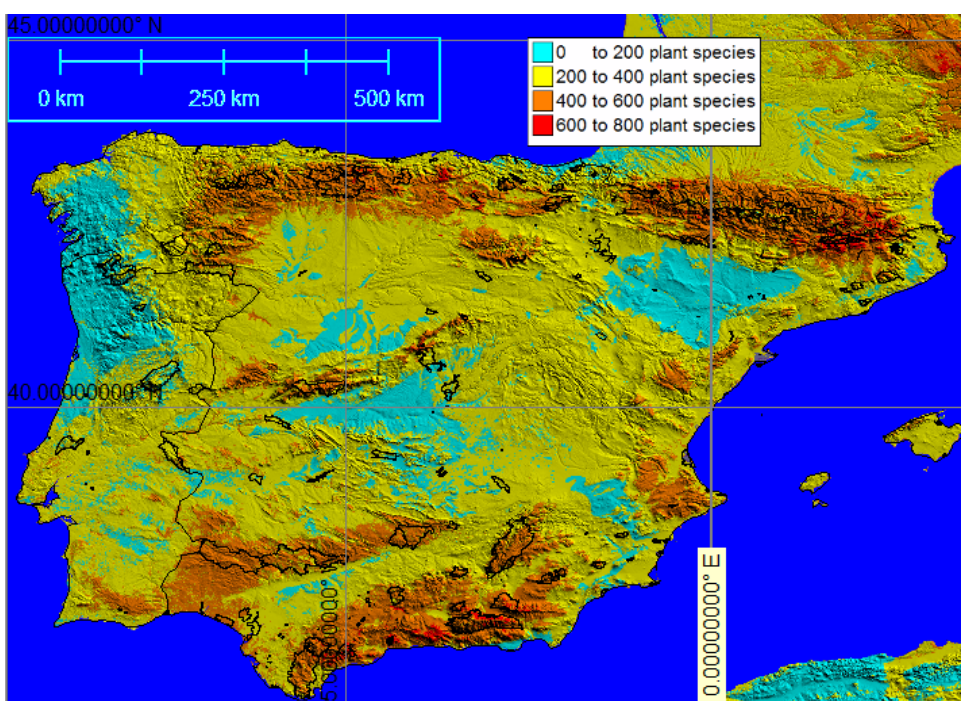

Figure 6. Total modelled plant species per 1-km grid cell across the Iberian Peninsula. 
ga Collserola Park (Barcelona) shows a net counter-tendency. Therefore, Font Groga could become a refuge for Catalonian flora.

Floristic diversity is largely projected to increase in the Los Alcornocales and Sierra de Grazalema Natural Parks of Andalusia and these projected biodiversity gains will be influenced by dynamic species able to conquer new spaces, pioneer species like ruderals or species belonging to seral communities (shrublands, etc.). Additionally, we note that these projected biodiversity gains might be illusive simply because we assumed a fixed $100 \%$ rate of establishment success at newly available sites which is not likely to happen for all species. Indeed, recipient communities might resist and limit the establishment success of new colonizers at newly suitable sites. In southeast Spain, the Sierra Nevada National Park will also become a high-biodiversity refuge (Figure 2(a)) except for biodiversity loss from summits [44]. However, here thermophilization is likely to play a role in the decline of cold-adapted species and increase in warm-adapted species [45].

There are 15 Spanish national parks administratively managed by the Spanish Institution for National Parks (an autonomous agency). Every year this institution finances different research projects to improve the scientific knowledge of biodiversity with a budget for the present year of €626,855. The nine National Parks in the Iberian Peninsula are identified in Figure 2(a), there are others, principally in the Canary Islands, that are not included in the present study. Additional sources of scientific knowledge funding for PAs but not specifically for the National Park net are: universities; central regional or local Spanish governments; and private foundations. Considering the limited financial resources available in recent years, Alagador, Cerdeira and Araújo [46] propose a detailed species-based methodology for identifying under-performing PAs with a dire biodiversity loss forecast so that they can be released and conservation efforts concentrated elsewhere. This study aids this goal by broadly identifying PAs with significant projected floristic diversity gains and losses under near-future climate change.

\section{Conclusion}

Considering that the biodiversity losses we calculated may have been overestimated due to potential persistence of remnant populations in climatic microrefugia [42] [47], our results encourage us to believe that with limited human assistance, floristic diversity contained by the current network of Iberian PAs can resist the onslaught of near-future climate change, although the long-term outlook for Iberian plant diversity is bleak [13] [48]. If greenhouse gas mitigation measures are adopted soon, this scenario may largely be avoided [48], but there is, as yet, no sign of a decline in accumulation of greenhouses gases [49]. Therefore, without the adoption of greenhouse gas mitigation measures, we consider that a conservation strategy, based on near-future climate change predictions that have greater data certainty, is a reasonable approach at the moment. This strategy permits the identification of species and habitats that are under immediate threat as well as protected areas where current biodiversity should prevail or increase and where conservation efforts should be focused.

\section{Supporting Information}

Appendix S1: MAXENT meta-data for the computed 3267 Iberian plant species ENMs ${ }^{1}$.

Appendix S2: Extirpated and critically endangered flora ${ }^{1}$.

Appendix S3: Student " $t$ " test values for range margin change ${ }^{1}$.

\section{References}

[1] Chen, I.C., Hill, J.K., Ohlemüller, R., Roy, D.B. and Thomas, C.D. (2011) Rapid Range Shifts of Species Associated with High Levels of Climate Warming. Science, 333, 1024-1026. http://dx.doi.org/10.1126/science.1206432

[2] Parmesan, C. and Yohe, G. (2003) A Globally Coherent Fingerprint of Climate Change Impacts across Natural Systems. Nature, 421, 37-42. http://dx.doi.org/10.1038/nature01286

[3] Lenoir, J., Gégout, J.C., Guisan, A., Vittoz, P., Wohlgemuth, T., et al. (2010) Going against the Flow: Potential Mechanisms for Unexpected Downslope Range Shifts in a Warming Climate. Ecography, 33, 295-303. http://dx.doi.org/10.1111/j.1600-0587.2010.06279.x

[4] Crimmins, S.M., Dobrowski, S.Z., Greenberg, J.A., Abatzoglou, J.T. and Mynsberge, A.R. (2011) Changes in Climatic

\footnotetext{
${ }^{1}$ Available from corresponding author upon request.
} 
Water Balance Drive Downhill Shifts in Plant Species’ Optimum Elevations. Science, 331, 324-327. http://dx.doi.org/10.1126/science.1199040

[5] VanDerWal, J., Murphy, H.T., Kutt, A.S., Perkins, G.C., Bateman, B.L., et al. (2013) Focus on Poleward Shifts in Species’ Distribution Underestimates the Fingerprint of Climate Change. Nature Climate Change, 3, 239-243. http://dx.doi.org/10.1038/nclimate1688

[6] Cannone, N. and Pignatti, S. (2014) Ecological Responses of Plant Species and Communities to Climate Warming: Upward Shift or Range Filling Processes? Climatic Change, 123, 201-214. http://dx.doi.org/10.1007/s10584-014-1065-8

[7] Lenoir, J. and Svenning, J.C. (2014) Climate-Related Range Shifts-A Global Multidimensional Synthesis and New Research Directions. Ecography. http://dx.doi.org/10.1111/ecog.00967

[8] Groom, Q.J. (2013) Some Poleward Movement of British Native Vascular Plants Is Occurring, but the Fingerprint of Climate Change Is Not Evident. PeerJ, 1, e77. http://dx.doi.org/10.7717/peerj.77

[9] Colwell, R.K., Brehm, G., Cardelús, C.L., Gilman, A.C. and Longino, J.T. (2008) Global Warming, Elevational Range Shifts, and Lowland Biotic Attrition in the Wet Tropics. Science, 322, 258-261. http://dx.doi.org/10.1126/science.1162547

[10] Feeley, K.J. and Silman, M.R. (2010) Biotic Attrition from Tropical Forests Correcting for Truncated Temperature Niches. Global Change Biology, 16, 1830-1836. http://dx.doi.org/10.1111/j.1365-2486.2009.02085.x

[11] Fernández-González, F., Loidi, J., Moreno, J.C., Del Arco, M., Férnández-Cancio, A., et al. (2005) Impactos sobre la biodiversidad vegetal. In: Moreno, J.M., Ed., Evaluación preliminar de los impactos en España por efecto del cambio climático, Ministerio de MedioAmbiente, Madrid, 183-248.

[12] Araújo, M.B., Alagador, D., Cabeza, M., Nogués-Bravo, D. and Thuiller, W. (2011) Climate Change Threatens European Conservation Areas. Ecology Letters, 14, 484-492. http://dx.doi.org/10.1111/j.1461-0248.2011.01610.x

[13] Thuiller, W., Lavorel, S., Araújo, M.B., Sykes, M.T. and Prentice, I.C. (2005) Climate Change Threats to Plant Diversity in Europe. Proceedings of the National Academy of Sciences of the United States of America, 102, 8245-8250. http://dx.doi.org/10.1073/pnas.0409902102

[14] Lenoir, J., Graae, B.J., Aarrestad, P.A., Alsos, I.G., Armbruster, W.S., Austrheim, G., et al. (2013) Local Temperatures Inferred from Plant Communities Suggest Strong Spatial Buffering of Climate Warming across Northern Europe. Global Change Biology, 19, 1470-1481. http://dx.doi.org/10.1111/gcb.12129

[15] Willis, K.J. and Bhagwat, S.A. (2009) Biodiversity and Climate Change. Science, 326, 806-807. http://dx.doi.org/10.1126/science.1178838

[16] Dullinger, S., Gattringer, A., Thuiller, W., Moser, D., Zimmermann, N.E., Guisan, A., et al. (2012) Extinction Debt of High-Mountain Plants under Twenty-First-Century Climate Change. Nature Climate Change, 2, 619-622. http://dx.doi.org/10.1038/nclimate1514

[17] Heap, M.J., Culham, A. and Osborne, J. (2013) The Benefits of a Compute Cluster Approach to High Spatial Resolution Biodiversity Richness Modelling: Projecting the Impact of Climate Change on Mediterranean Flora. The International Journal of Climate Change: Impacts and Responses, 4, 115-218.

[18] Thuiller, W., Albert, C., Araújo, M.B., Berry, P.M., Cabeza, M., Guisan, A., et al. (2008) Predicting Global Change Impacts on Plant Species’ Distributions: Future Challenges. Perspectives in Plant Ecology, Evolution and Systematics, 9, 137-152. http://dx.doi.org/10.1016/j.ppees.2007.09.004

[19] Yesson, C. and Culham, A. (2006) A Phyloclimatic Study of Cyclamen. BMC Evolutionary Biology, 6, 72. http://dx.doi.org/10.1186/1471-2148-6-72

[20] Phillips, S.J., Anderson, R.P. and Schapire, R.E. (2006) Maximum Entropy Modeling of Species Geographic Distributions. Ecological Modelling, 190, 231-259. http://dx.doi.org/10.1016/j.ecolmodel.2005.03.026

[21] Hijmans, R.J., Cameron, S.E., Parra, J.L., Jones, P.G. and Jarvis, A. (2005) Very High Resolution Interpolated Climate Surfaces for Global Land Areas. International Journal of Climatology, 25, 1965-1978. http://dx.doi.org/10.1002/joc.1276

[22] FAO and ISRIC (2010) Harmonized World Soil Database (Version 1.1). FAO, Rome and IIASA, Laxenburg.

[23] Hansen, M., DeFries, R., Townshend, J.R.G. and Sohlberg, R. (1998) UMD Global Land Cover Classification, 1 Kilometer, 1.0. Department of Geography, University of Maryland, College Park, 1981-1994.

[24] Pliscoff, P., Luebert, F., Hilger, H.H. and Guisan, A. (2014) Effects of Alternative Sets of Climatic Predictors on Species Distribution Models and Associated Estimates of Extinction Risk: A Test with Plants in an Arid Environment. Ecological Modelling, 288, 166-177. http://dx.doi.org/10.1016/j.ecolmodel.2014.06.003

[25] Ramirez-Villegas, J. and Jarvis, A. (2010) Downscaling Global Circulation Model Outputs: The Delta Method Decision and Policy Analysis. Working Paper No. 1, Policy Analysis 1, 1-18. 
[26] Thiers, B. (2011) Continuously Updated. Index Herbariorum: A Global Directory of Public Herbaria and Associated Staff. New York Botanical Garden’s Virtual Herbarium. http://sciweb.nybg.org/science2/IndexHerbariorum.asp http://sweetgum.nybg.org/ih/

[27] Yesson, C., Brewer, P.W., Sutton, T., Caithness, N., Pahwa, J.S., Burgess, M. and Culham, A. (2007) How Global Is the Global Biodiversity Information Facility? PLOS ONE, 2, e1124. http://dx.doi.org/10.1371/journal.pone.0001124

[28] Heap, M.J. and Culham, A. (2010) Automated Pre-Processing Strategies for Species Occurrence Data Used in Biodiversity Modelling. In: Setchi, R., Jordanov, I., Howlett, R.J. and Jain, L.C., Eds., Knowledge-Based and Intelligent Information and Engineering Systems, Springer Berlin Heidelberg, Berlin, 517-526. http://dx.doi.org/10.1007/978-3-642-15384-6 55

[29] Castroviejo, S. (1986) Flora iberica: Plantas vasculares de la Península Ibérica e Islas Baleares.

[30] Casas, C. (1998) The Anthocerotae and Hepaticae of Spain and Balearic Islands: A Preliminary Checklist. Orsis, 13, 17-26.

[31] Rivas-Martínez, S., Diaz, T.E., Fernandez-Gonzalez, F., Izco, J., Loidi, J., Lousã, M. and Penas, Á. (2002) Vascular Plant Communities of Spain and Portugal: Addenda to the Syntaxonomical Checklist of 2001. Itinera Geobotanica, 15, 5-922.

[32] Euro+Med (2006) Euro+Med PlantBase-The Information Resource for Euro-Mediterranean Plant Diversity. http://ww2.bgbm.org/EuroPlusMed/

[33] The Plant List (2010) Version 1. http://www.theplantlist.org/

[34] Ros, R.M., Mazimpaka, V., Abou-Salama, U., Aleffi, M., Blockeel, T.L., et al. (2013) Mosses of the Mediterranean, an Annotated Checklist. Cryptogamie, Bryologie, 34, 99-283. http://dx.doi.org/10.7872/cryb.v34.iss2.2013.99

[35] Roskov, Y., Kunze, T., Paglinawan, L., Orrell, T., Nicolson, D., et al. (2013) Species 2000 \& ITIS Catalogue of Life. 2013 Annual Checklist, Species 2013.

[36] Encyclopedia of Life (2014) http://www.eol.org.

[37] Pittman, S.J. and Brown, K.A. (2011) Multi-Scale Approach for Predicting Fish Species Distributions across Coral Reef Seascapes. PloS ONE, 6, e20583. http://dx.doi.org/10.1371/journal.pone.0020583

[38] Morin, X. and Thuiller, W. (2009) Comparing Niche- and Process-Based Models to Reduce Prediction Uncertainty in Species Range Shifts under Climate Change. Ecology, 90, 1301-1313. http://dx.doi.org/10.1890/08-0134.1

[39] Brommer, J.E. (2004) The Range Margins of Northern Birds Shift Polewards. Annales Zoologici Fennici, 41, $391-397$.

[40] Heubes, J., Schmidt, M., Stuch, B., García Márquez, J.R., Wittig, R., Zizka, G., et al. (2013) The Projected Impact of Climate and Land Use Change on Plant Diversity: An Example from West Africa. Journal of Arid Environments, 96, 48-54. http://dx.doi.org/10.1016/j.jaridenv.2013.04.008

[41] Gavilán, R.G. (2005) The Use of Climatic Parameters and Indices in Vegetation Distribution. A Case Study in the Spanish Sistema Central. International Journal of Biometeorology, 50, 111-120. http://dx.doi.org/10.1007/s00484-005-0271-5

[42] Hampe, A. and Jump, A.S. (2011) Climate Relicts: Past, Present, Future. Annual Review of Ecology, Evolution, and Systematics, 42, 313-333. http://dx.doi.org/10.1146/annurev-ecolsys-102710-145015

[43] Thomas, C.D. (2011) Translocation of Species, Climate Change, and the End of Trying to Recreate Past Ecological Communities. Trends in Ecology \& Evolution, 26, 216-221. http://dx.doi.org/10.1016/j.tree.2011.02.006

[44] Pauli, H., Gottfried, M., Dullinger, S., Abdaladze, O., Akhalkatsi, M., Alonso, J.L.B., et al. (2012) Recent Plant Diversity Changes on Europe’s Mountain Summits. Science, 336, 353-355. http://dx.doi.org/10.1126/science.1219033

[45] Gottfried, M., Pauli, H., Futschik, A., Akhalkatsi, M., Barančok, P., Alonso, J.L.B., et al. (2012) Continent-Wide Response of Mountain Vegetation to Climate Change. Nature Climate Change, 2, 111-115. http://dx.doi.org/10.1038/nclimate1329

[46] Alagador, D., Cerdeira, J.O. and Araújo, M.B. (2014) Shifting Protected Areas: Scheduling Spatial Priorities under Climate Change. Journal of Applied Ecology, 51, 703-713. http://dx.doi.org/10.1111/1365-2664.12230

[47] Dobrowski, S.Z. (2011) A Climatic Basis for Microrefugia: The Influence of Terrain on Climate. Global Change Biology, 17, 1022-1035. http://dx.doi.org/10.1111/j.1365-2486.2010.02263.x

[48] Warren, R., Van DerWal, J., Price, J., Welbergen, J.A., Atkinson, I., Ramirez-Villegas, J., et al. (2013) Quantifying the Benefit of Early Climate Change Mitigation in Avoiding Biodiversity Loss. Nature Climate Change, 3, 678-682. http://dx.doi.org/10.1038/nclimate1887

[49] Dlugokencky, E. and Tans, P. (2014) NOAA/ESRL. http://www.esrl.noaa.gov/gmd/ccgg/trends/ 
Scientific Research Publishing (SCIRP) is one of the largest Open Access journal publishers. It is currently publishing more than 200 open access, online, peer-reviewed journals covering a wide range of academic disciplines. SCIRP serves the worldwide academic communities and contributes to the progress and application of science with its publication.

Other selected journals from SCIRP are listed as below. Submit your manuscript to us via either submit@scirp.org or Online Submission Portal.
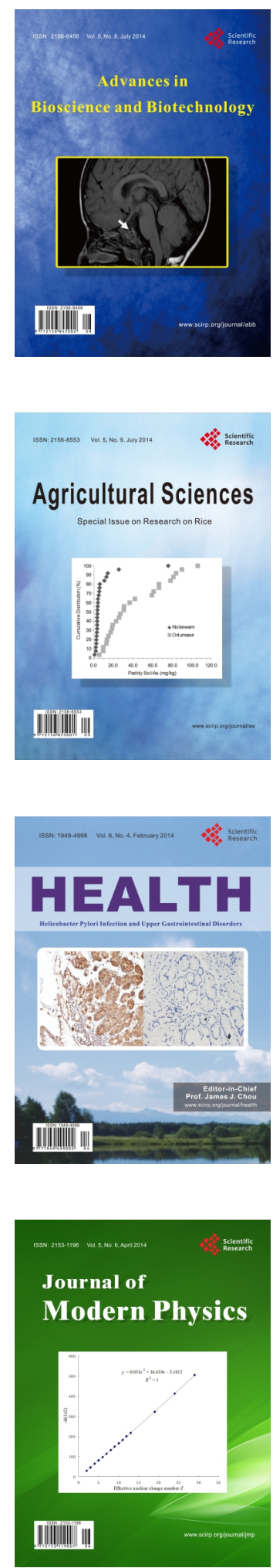
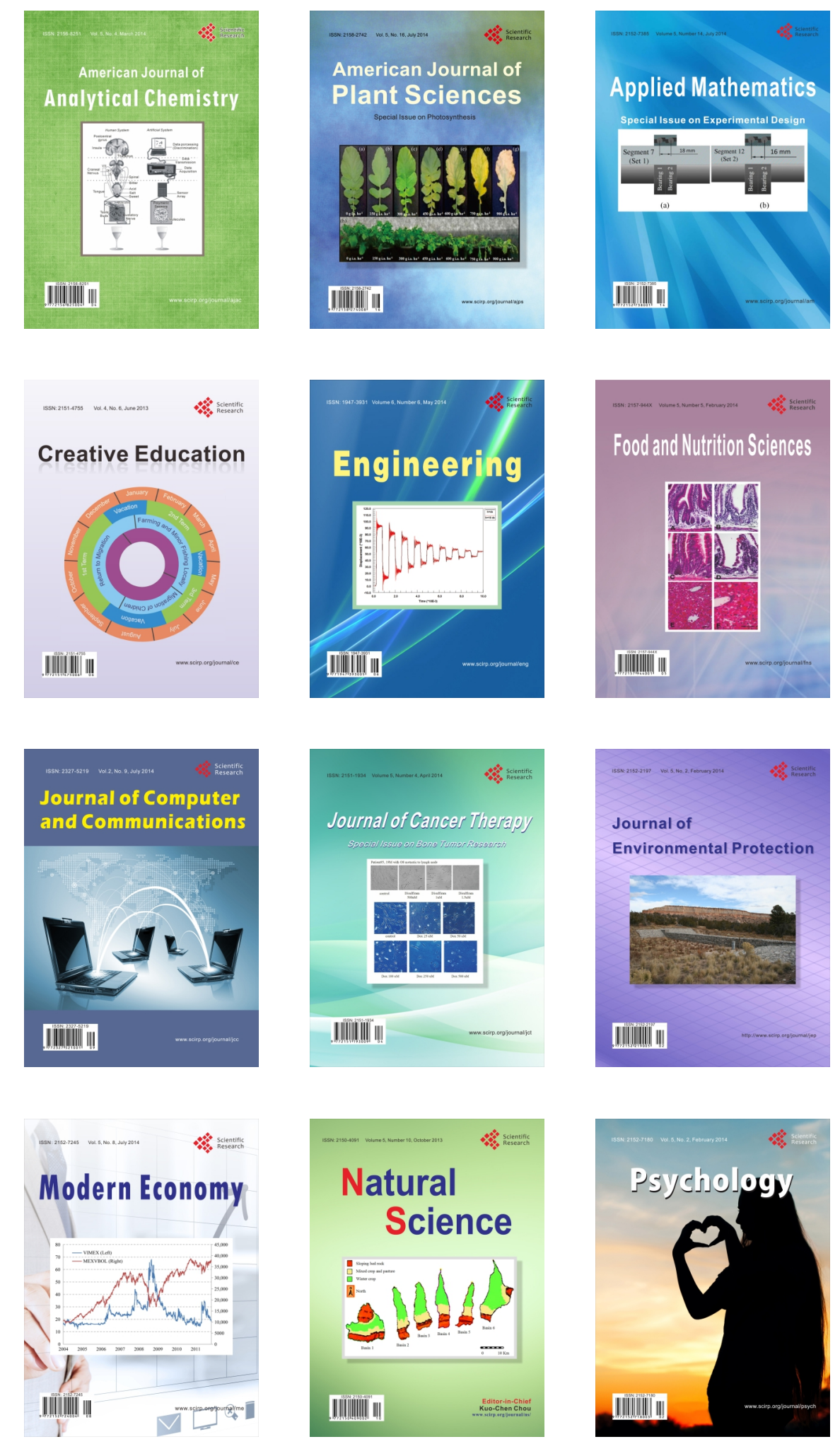